\title{
Covariation of depressive symptoms, parkinsonism, and post-dexamethasone plasma cortisol levels in a bipolar patient: simultaneous response to ECT and lithium carbonate
}

\author{
R. S. Jaeckle and S. C. Dilsaver \\ University of lowa, Psychiatric Hospital, and \\ University of Michigan, Dept. of Psychiatry, Ann \\ Arbor, U.S.A.
}

\begin{abstract}
A patient presented with concurrent mood congruent delusions, parkinsonism, and elevated post-dexamethasone plasma cortisol levels. This triad could result from simultaneous development of cholinergic-monoaminergic dysfunction within critical limbic and extrapyramidal loci. The magnitude of each abnormality decreased in concert during a course of electroconvulsive therapy (ECT). Remaining abnormalities disappeared during treatment with lithium. Actions of ECT and lithium on muscarinic systems are reviewed, and a strategy for testing the hypothesis that dysfunction of cholinergic-monoaminergic mechanisms develops in parallel in different neural networks is considered.
\end{abstract}

Received July 9, 1985; accepted for publication January 25, 1986

Endogenous depression and Parkinson's disease may share neurotransmitter dysfunctions. In one major study $90 \%$ of all patients with Parkinson's disease had depressive symptomatology (1). Patients with parkinsonism or Parkinson's disease also exhibit significantly increased frequencies of depressive symptoms compared to controls $(2,3)$. We present a patient with bipolar I disorder who exhibits the features of Parkinson's disease during depressive episodes. Severity of depression, parkinsonism and the 4 p.m. Day II post dexamethasone plasma cortisol concentration decreased in parallel in the course of receiving consecutive treatment with electroconvulsive therapy (ECT) and lithium. Discussion focuses on the effects of ECT and lithium on the dynamics of cholinergic-monoaminergic interaction.

\section{Case report}

Mrs. A, 59-year-old post-menopausal woman was admitted to the Clinical Studies Unit for Affective Disorders (CSU) at the University of Michigan Medical Center, with a 3-month history of depressed mood, anhedonia, loss of libido, social withdrawal, anergy, ruminations over previous real or imagined failures, hopelessness, suicidal ideation, early, middle, and terminal insomnia, anorexia, a $15 \mathrm{lb}$. weight loss, constipation, difficulty concentrating, "inability to think," marked retardation of speech and movement, and the conviction that she had uncontrollable diarrhea. She had three previous episodes of depression fulfilling Research Diagnostic Criteria (RDC) (4) for major depressive disorder (MDD), endogenous subtype. Her first 
episode, at 36, occurred post-partum. All episodes responded well to ECT. She had at least one episode of mania by RDC for which she was treated with antipsychotic agents. She was asymptomatic for several years prior to admission to the CSU. She fulfilled RDC for recurrent primary MDD, endogenous subtype with psychotic features, and bipolar I disorder, and also met DSM-III (5) criteria for bipolar affective disorder and MDD with melancholia and psychotic features.

The referring internist and her family reported progressive bradykinesia, masked facies, stooped posture, shuffling gate, and resting tremor in the course of the current episode. Two months following onset of depressed mood and extrapyramidal signs, amitriptyline hydrochloride, $75 \mathrm{mg}$ q.h.s., thiothixene $5 \mathrm{mg} \mathrm{q.h.s.,} \mathrm{and} \mathrm{benztropine} \mathrm{mesylate}$ $1 \mathrm{mg}$ b.i.d. were started. These drugs were used 2 weeks before presentation at the CSU. At that time all medications were discontinued in accordance with policies governing the diagnostic and research evaluation of CSU inpatients. No other psychotropics were used in the course of the current episode. Multiple interviews with relatives and Mrs. A's primary physician disclosed previous depressive episodes marked by bradykinesia, masked facies, stooped posture, shuffling gate, cogwheel rigidity and resting tremor, always resolving in the course of ECT. Signs of extrapyramidal system dysfunction were not evident during her manic episode, even though it was treated with antipsychotics. Mrs. A was not treated with antidepressants, antiparkinsonian-agents or lithium carbonate prior to the current episode. There was no family history of psychiatric or neurologic illness.

The admission mental status examination revealed severe depression characterized by the previously noted signs and symptoms. The 17item Hamilton Rating Scale for Depression HRSD) (6) score was 32 . Her score was $20 / 30$ on the mini-mental status examination (7). She failed on items demanding concentration, memory, and duplication of visually presented figures. Neurological examination revealed bradykinesia, cogwheel rigidity in all extremities, masked facies, stooped posture, shuffling and fenestrating gate, slowed, soft, monotonal speech, micrographia and pin-rolling tremor. There was no other evidence of extrapyramidal system dysfunction.

The routine CSU laboratory screen includes a SMA-12, CBC and differential, urinalysis, serum VDRL, vitamine B 12 and folate levels, determination of tetraiodothyronine $\left(\mathrm{T}_{4}\right)$, triodothyronine $\left(\mathrm{T}_{3}\right)$, and thyroid stimulating hormone (TSH) levels by RIA, an electrocardiogram (EKG) and a chest radiogram. All results were within normal limits. A computerized axial tomographic (CAT) scan of the brain was also unremarkable. The admission dexamethasone suppression test (DST), conducted by the method of Carroll et al. (8), was positive. The 4 p.m. and 11 p.m. post-dexamethasone cortisol levels were 8.2 and $14.0 \mu \mathrm{g} / \mathrm{dl}$, respectively. On the basis of historical information, cross-sectional assessment, and laboratory data, we concluded that Mrs. A had pseudodementia consequent to an endogenous depression (9).

A 4-point global severity extrapyramidal signs scale (EPS) was completed every 7 days. The HRSD, EPS and DST were completed on the same day each week. HRSD and EPS ratings were completed at 4:00 p.m. so as to minimize variance due to circardian factors affecting mood, DST status, and motor activity. Rating scales were always completed by the same investigator (R.S.J.), blind to DST results. Weekly

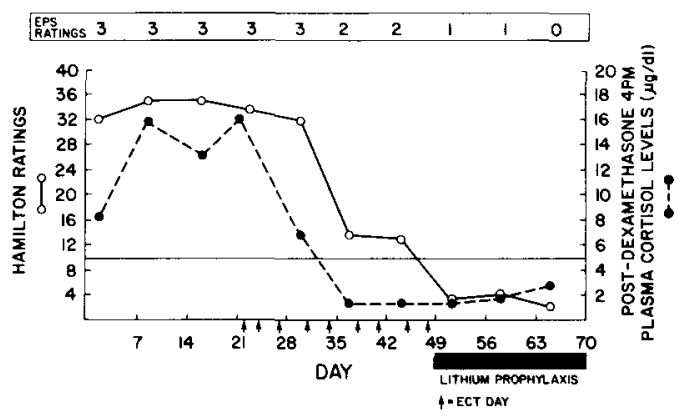

Fig. I. The plasma cortisol assay measures total plasma corticosteroids by the competitive protein binding technique of Murphy (1967) as modified by Hsu and Bledsoe (1967) and Beardwell (1968). Intra-assay C.V. = $6.5 \%$, Intera-ssay C.V. $=12.5 \%$ when the mean plasma cortisol level is in the range of $2.5 \mu \mathrm{g} / \mathrm{dl}$ to $9 \mu \mathrm{g} / \mathrm{dl}$ 
HRSD, 4 p.m. post-dexamethasone plasma cortisol levels and EPS ratings are presented in Fig. 1 as a function of time in hospital. Note that days of ECT and lithium administration are specified.

Atropine sulfate, given prior to induction of anesthesia, and thiopentol, employed as a general anesthetic during ECT treatments, were the only psychoactive agents administered in hospital before starting lithium. Thiothixene, amitriptyline and benztropine were discontinued 5 weeks prior to starting the course of ECT during the 4th week of hospitalization. During the evaluation phase, covering the first 3 weeks of hospitalization, Mrs. A remained severely depressed and delusional. The EPS rating, 3 out of $4(3 / 4)$ on admission, did not change prior to starting ECT. The highest 4 p.m. post-dexamethasone plasma cortisol level was $15.9 \mu \mathrm{g} / \mathrm{dl}$.

Mrs. A received nine bilateral, frontotemporal ECT treatments over 4 weeks. After the fifth treatment, she was no longer delusional and her HRSD score was 14. Bradykinesia, masked facies, stooped postures, fenestrating gait, and resting tremor decreased. Nonetheless, the EPS score was $2 / 4$ due to persisting mild bradykinesia, shuffling gait, and cogwheel rigidity. Both 4 p.m. and 11 p.m. post-dexamethasone levels were within normal limits ( 1.3 and $2.0 \mu \mathrm{g} /$ $\mathrm{dl}$, respectively). Following the ninth ECT treatment, Mrs. A entered an operationally defined remission (HRSD score $<9$ ). At this time, her HRSD score was 3 and she responded normally to challenge with dexamethasone. During the 7th week of hospitalization, Mrs. A's EPS score was $1 / 4$ due to cogwheel rigidity in the upper extremities.

Treatment with lithium was instituted during week 8 , and by discharge at the end of week 10 Mrs. A's plasma lithium level was $0.92 \mathrm{mEq} / \mathrm{l}$ on a regime of $600 \mathrm{mg}$ b.i.d. HRSD scores remained below 4 and there was no cognitive impairment. She scored $30 / 30$ on the mini-mental status examination. Treatment with lithium was associated with a gradual disappearance of upper extremity cogwheel rigidity over a period of weeks. Discharge EPS score was 0/4. The 4 p.m. post-dexamethasone plasma cortisol levels continued to be within normal limits during weeks 8-10, though two 11 p.m. levels (5.19 and $14.37 \mu \mathrm{g} / \mathrm{dl}$ ) were elevated during this period.

One of us (S.C.D.) has been following Mrs. A since discharge 20 months ago. Lithium levels have fluctuated between 0.5 and $1 \mathrm{mEq} / 1$. She remains asymptomatic and without parkinsonism. A DST done 3 months after discharge was within normal limits (4 p.m. post-dexamethasone cortisol level $=2.0 \mu \mathrm{g} / \mathrm{dl}$ ).

\section{Discussion}

Covariation of depressive symptomatology, parkinsonism, and post-dexamethasone plasma cortisol levels suggests the possibility of shared underlying mechanisms. Abnormalities of cholinergic and dopaminergic systems are documented characteristics of Parkinson's disease (10) Parkinson's disease is accompained by decreased brain and cerebral spinal fluid dopamine and dopamine metabolite concentrations (10). Endogenously depressed patients with psychomotor retardation exhibit this (11). Serotonergic and noradrenergic pathophysiology is involved in the etiology of basal ganglia disorders (12). Others have reported that endogenous depression is also marked by decreased turnover and synaptic activity of serotonin (13) and norepinephrine $(14,15)$. These points indicate that endogenous depression and parkinsonism involve similar disturbances of monoaminergic mechanisms. Serotonergic and noradrenergic (16) mechanisms may be involved in the pathophysiology of Parkinson's disease via regulation of acetylcholine release from striatal cholinergic neurons. Dilsaver \& Greden (17) propose that similar mechanisms may be operative in mesolimbic regions involved in the regulation of mood and affect. Data indicate that endogenous depression and mania are associated with dysfunction of cholinergic and monoaminergic systems, or aberrant cholinergic-monoaminergic interaction in limbic regions involved in the regulation of mood, drive reduction behavior, sleep onset, and staging and autonomic, neuroendocrine and psychomotor functions. First, muscarinic cholinergic system supersensitivity is implicated in the pathophysiology of the phe- 
nomenologic aspects of affective disorders (18). Resistance to dexamethasone challenge may also involve this mechanism (19). This is consistent with observations indicating that physostigmine induces non-suppression to dexamethasone challenge in normal subjects $(20,21)$. Risch and colleagues $(22,23)$ showed that affective disorder patients exhibit supersensitivity to physostigmine-induced release of ACTH and $\beta$-endorphin compared to normal and psychiatric control subjects. Janowsky et al. (19) reported significant correlations between rises in absolute post-dexamethasone plasma cortisol and ACTH levels, dysphoria and psychomotor retardation in subjects with MDD, endogenous subtype, during physostigmine infusion.

Psychiatric and neuroscience reports emphasize effects of ECT and lithium on monoaminergic networks. Holcomb et al. (24) described the progress of a patient with MDD, psychotic subtype (4), intra-episode parkinsonism, and tardive dyskinesia during two courses of ECT. Mood and parkinsonism improved in parallel while tardive dyskinesia worsened. They reviewed 23 cases of patients with parkinsonism receiving ECT. Sixteen, including all with affective illness, demonstrated a marked improvement in motor function. They concluded that this accords with the capacity of ECT to enhance the sensitivity of post-synaptic dopamine receptors and decrease the responsiveness of dopamine autoreceptors to dopamine agonists $(25,26)$. Pharmacologic agents which enhance the action of dopamine at central receptor sites, such as levo-dopa, bromocriptine, monoamine oxidase inhibitors, and tricyclic antidepressants (27-34) are effective in treating both endogenous depression (7) and Parkinson's disease. However, ECT, lithium and thymolytics modify noradrenergic (15), serotonergic (35), and muscarinic cholinergic (36-42) systems in addition to changing dopaminergic variables. Further, ECT (36-40) and lithium $(41,42)$ down-regulate cholinergic receptors. Lithium also prevents anticholinergicinduced muscarinic receptor up-regulation (42). ECT and lithium also increase the function of adrenergic, serotonergic and dopaminergic systems. Treatments down-regulating muscarinic receptors, or diminishing the net activity of cho- linergic systems while potentiating monoaminergic receptor function, should alleviate parkinsonism. This, prima facie, conflicts with the efficacy of ECT and lithium in treating mania. However, lithium and ECT may stabilize, or render less perturbable, cholinergic and monoaminergic systems. This may be essential to their clinical utility.

Covariation of changes in depressive symptoms, parkinsonism, and post-dexamethasone plasma cortisol levels, might be due to imbalances of cholinergic-monoaminergic systems at critical central loci systems which change in parallel. Quantifiable indices subject to cholinergic-monoaminergic influences are: rate of salivary production, pupillary dynamics, body temperature, REM latency and density, and CGMP and phospholipid turnover (43). These and other physiological and biochemical endpoints can be used to study cholinergic-monoaminergic dynamics with standardized accurate methods of measurement.

Patients exhibiting Mrs. A's features may not be common but the anomalous and atypical often raise questions of greater heuristic value than does the mundane. Measurement of two or three physiological endpoints subject to cholinergic and monoaminergic influences can render the study of individual patients useful in testing specific hypotheses.

\section{References}

1. Mindham R H S. Psychiatric symptoms in parkinsonism. J Neurol Neurosurg Psychiatry 1970:33:188.

2. Horne S. Some psychological factors in parkinsonism. J Neurol Neurosurg Psychiatry 1974:37:27-31.

4. Spitzer R L, Endicott J, Robbins E. Research Diagnostic Criteria. 2nd ed., New York State Department of Mental Hygiene, New York Psychiatric Institute, Biometrics Research, 1975.

5. Diagnostic and Statistical Manual of the American Psychiatric Association, 3rd ed., Washington, D.C., 1980.

6. Hamilton M. A Rating Scale for Depression. J Neurol Neurosurg Psychiatry 1962:23:56-62.

7. Blessed $G$, Tomlinson $B$, Roth $M$. The association between quantitative measures of dementia and senile change in the cerebral gray matter of elderly subjects. $\mathrm{Br} \mathrm{J}$ Psychiatry 1968:/14:797-811.

8. Carroll B J, Feiberg M, Greden J F, et al. A specific laboratory test for the diagnosis of melancholia. Arch Gen Psychiatry 1981:38:15-22. 
9. Grunhaus L, Dilsaver S C. Greden J F, Carroll B J. Depressive pseudodementia: A suggested diagnostic profile. Biol Psychiatry 1983:18:215-225.

10. Hornykiewicz $O$. Brain neurolransmitters in Parkinson's disease. In: Marsden C D, Fahn S, eds. Movement disorders. London: B. Herworths, 1982:41-58.

11. van Praag $H$ M, Korf J. Retarded depression in the dopamine metabolism. Psychophamacology 1971:/8:199203.

12. Penny J B, Young A B. Speculations on the functional anatomy of basal ganglia disorders. Ann Rev Neurosci 1983:6:73-94

13. van Praag $H$ M. Depression, suicide and serotonin metabolism of the brain. In: Post R M, Ballenger $J$, eds. The neurobiology of manic-depressive illness. Baltimore: Williams and Wilkins, 1971.

14. Goodwin F K, Potter W Z. Noradrenergic function in affective illness. In: Saletu B, Berner P, Holister I., eds. Neuropsychopharmacology. New York: Pergamon Press, 1979:127-137

15. Charney D S, Menkes D B, Heninger G R. Receptor sensitivity in the mechanism of action of antidepressant treatment. Arch Gen Psychiatry 1981:38:1160-1180.

16. Vizi E S, Pasztor E. Relase of acetylcholine from isolated human cortical slices: inhibitory effect of norepinephrine and phenytoin. Exp Neurol 1981:73:144-153.

17. Dilsaver S C, Greden J F. Activation on antidepressant withdrawal: A possible mechanism and its theoretical significance. Brain Res Rev 1984:7:29-48.

18. Dilsaver S C. Pathophysiology of cholinoceptor supersensitivity in affective disorders. Biol Psychiatry (in press 1986).

19. Janowsky D S, Risch S C, Huey L Y, Judd L, Raush J L. Hypothalamic-pituitary-adrenal regulation: Neurotransmitters and affective disorders. Peptides 1983:4:775-784.

20. Carroll B J, Greden J F, Haskett R, et al. Neurotransmitter studies of neuroendocrine pathology in depression. Acta Psychiatr Scand 1980:61,Suppl 280:183-199.

21. Doerr P Berger M. Physostigmine-induced escape from dexamethasone in normal subjects. Biol Psychiatry 1983: I8:216-268

22. Risch S C, Janowsky D S, Gillin J C. Muscarinic supersensitivity of anterior pituitary ACTH and beta-endorphin release in major depressive illness. Peptides 1983:4:789792.

23. Risch S C. B-endorphin hypersecretion in depression: Possible cholinergic mechanisms. Biol Psychiatry 1982:17;1071-1079.

24. Holcomb H H, Stenberg A E, Heninger G R. Effect of electroconvulsive therapy on mood, parkinsonism, and tardive dyskinesia in a depressed patient: ECT and dopamine systems. Biol Psychiatry 1983:18:865-873.

25. Chido L. A, Antelman S M. Electroconvulsive shock, progressive dopamine autoreceptor subsensitivity independent of repeated treatment. Science 1980:210:799.

26. Lerer B, Belmaker R H. Receptors and the mechanism of action of ECT. Biol Psychiatry 1982:17:497-511.

27. Lieberman A, Glofaghari M, Boal D et al. The antiparkinsonian efficacy of bromocriptine. Neurology 1976: 26:405-409.
28. Marsden ( D, Parkes J D. Success and problems of long term levo-dopa therapy in Parkinson's disease. I ancel 1977:2:345-349.

29. Schwab R S, England A C, Poskanzer D C, Young R R. Amantadine in the treatment of Parkinson's disease. $J$ Am Med Assoc 1969:208:1168-1170.

30. Birkmeyer $W$, Riederer P, Ambrozi L, Yodim M B H Implication of combined treatment with "Modapar" and L-deprenyl in Parkinson's disease. Lancet: I:439-440.

31. Knoll J. The possible mechanisms of action of (-)deprenyl in Parkinson's disease. J Neural Transm 1978:43:177-198.

32. Yahr M D. A review of present day treatment of Parkinson's disease. J Neural Transm 1978:43:79-84.

33. Bianchine J R. Drugs for Parkinson's disease. In: Gilman A G, Goodman L S, Gilman A, eds. 6th ed. The pharmacological basis of therapeutics. New York: Macmillan, 1980:484

34. Himwich H E, Alpers H S. Psychopharmacology. An Rev Pharmacol 1970:10:313.

35. Fuxe $\mathrm{K}$, et al. Chronic antidepressant treatment in central 5-HT synapses. Neuropharmacology 1983:22:389-400.

36. Dasheiff R M, Byrne M C, Patroni U, McNamara J O. Biochemical evidence of decreased cholinergic neuronal communication following amygdala kindled seizures. Brain Res 1981:206:233-238.

37. Dasheiff R M, Savage D D, McNamara J O. Seizures down-regulate muscarinic cholinergic receptors in hippocampal formation. Brain Res 1982:235:327-334

38. Dasheiff $\mathrm{R} \mathbf{J}$, McNamara $\mathbf{J} \mathrm{O}$. Evidence for an anonisi independent down-regulation of hippocampal muscarinic receptors in kindling. Brain Res 1980:195:345-353.

39. Pestronk A, Drachman D B. Lithium reduces the number of acetylcholine receptors in skeletal muscle. Science 1980:210:342.

40. Byrne M C, Gottlieb N, McNamara T O. Amygdala kindling induces muscarinic cholinergic receptor declines in a highly specific distribution within the limbic system. Symp Neurol 1980:69:85-98.

41. Dilsaver S C. Effects of lithium on muscarinic receptor binding parameters: A relationship to therapeutic efficacy? Biol Psychiatry 1984:19:1551-1564.

42. Levy A, Zohar J, Belmaker R H. The effect of chronic lithium pretreatment in rat brain muscarinic receptor reg ulation. Neuropharmacology 1982:21:1199-1201.

43. Dilsaver S C. Pharmacologic induction of cholinergic system supersensitivity in affective disorders research. J Clin Psychophamacology (in press, 1986).

Address

Steven C. Dilsaver, M.D.

Clinical Studies Unit of Affective Disorders

Department of Psychiatry

Mental Health Research Institute and Neuroscience Laboratory

University of Michigan

Neuroscience Laboratory Building

1103 East Huron

Ann Arbor, Michigan 48104-1687

U.S.A. 